\title{
Caminhando entre mortos - o monumento moderno
}

\section{Guilherme Bueno ${ }^{1}$}

Resumo: O artigo analisa a partir de monumentos projetados por Walter Gropius, Mies van der Rohe, Rachel Whiteread e Peter Eisenman quais as implicações de uma nova simbolização da morte frente a eventos traumáticos do século XX. Para tanto, em certas passagens são discutidas questões formais ladeadas pela abordagem do luto em Freud.

Palavras-chave: monumento, holocausto, arte e arquitetura: século XX

\section{Walking with the deaths - the modern monument}

Abstract: This paper focuses a group of monuments designed by Walter Gropius, Mies van der Rohe, Rachel Whiteread and Peter Eisenman which deals with a new simbolism of death facing traumatic events of 20th. century history. In it, some formal questions are connected with the notion of mourning proposed by Freud.

Keywords: monument, holocaust, 20th century art and architecture.

1 Professor da Escola de Belas Artes da UFMG. Doutor em Artes Visuais pela UFRJ, lecionou no Instituto de Artes da UERJ (no qual é colaborador do PPGARTES), no Departamento de Arquitetura e Urbanismo da PUC-Rio e na Escola de Artes Visuais do Parque Lage. Pesquisador do PROARQ-FAU-UFRJ. Universidade Federal de Minas Gerais (EBAUFMG). E-mail: buenog@ufmg.br. ORCID: https://orcid.org/0000-0002-7962-1648. Lattes iD: http://lattes.cnpq. br/1143844954653469. Belo Horizonte, Brasil 


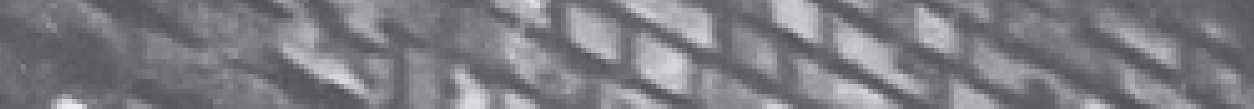

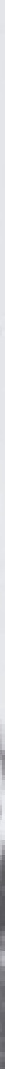
$12=$

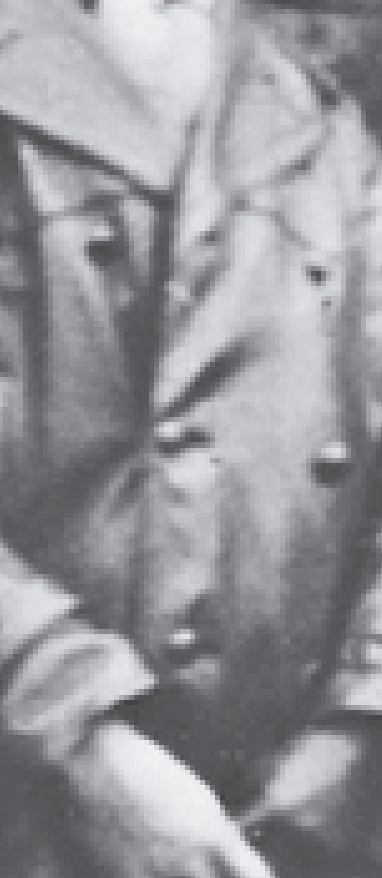

N

N
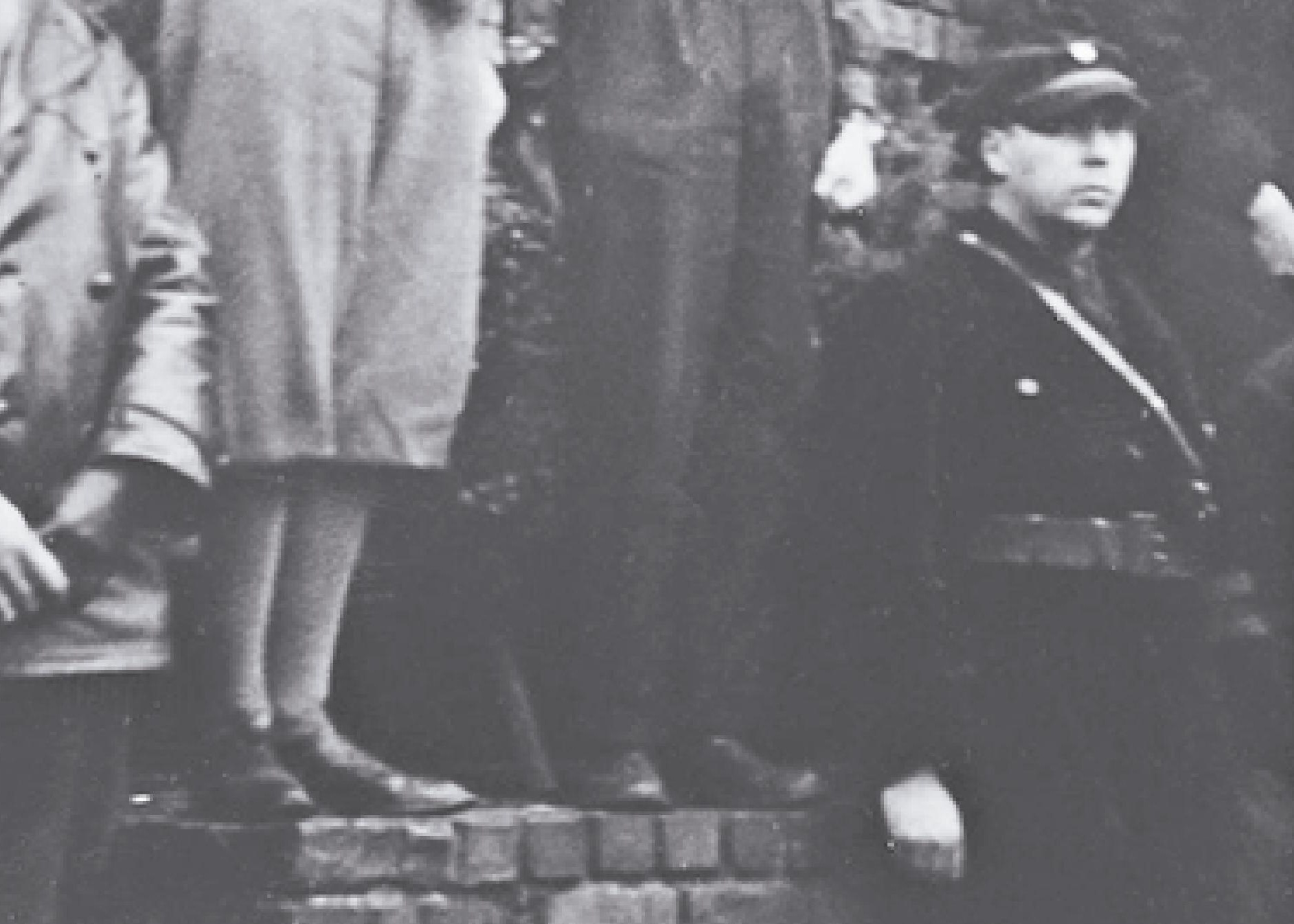

4 
All'ombra de cipressi e dentro l'urne, Confortate di pianto è forse il sonno

Della morte men duro?

Ugo Foscolo, Dei Sepolcri

O que é o monumento, mais especificamente, o monumento moderno? Recorrendo a dois extremos - o de fundação e o de clivagem da modernidade -, ele atrita uma ideia convencional da arte do século $X X$ baseada na separação dos meios: citada a visão de Hegel, ele é a epítome da contaminação de categorias, pois inscreve-se no ponto de contato (e transição) entre arquitetura e escultura ${ }^{1}$; em outra ponta (Hal Foster), sua potência está em problematizar o liame entre a separação da escultura e a escala da arquitetura, considerando haver um lugar de mensuração relacional do sujeito que implique numa indagação de sua corporeidade ${ }^{2}$.

Não importa requentar o moderno à luz do entrave do "domínio de competência", nem reavivar o atrito anacrônico a respeito de um ponto otimizado e idealizado que potencialize a autonomia do objeto (o cubo branco) e do sujeito; outrossim, essencialmente modernista é a assunção da forma - figurativa ou não - simbolizar um significado, efetivamente objetualiza-lo, ou, se quisermos tomar de empréstimo um termo freudiano, dela assumir um valor de transferência (ao final, voltaremos a esse ponto). Sob esse ângulo, ainda que haja uma inflexão contraditória na hipótese de um monumento

1 Hegel fala das "obras arquiteturais intermediárias entre a escultura e a arquitetura", exemplificadas por colunas fálicas, obeliscos, Mémnons, pátios de colunatas, labirintos, dentre outros. Ver a esse respeito: HEGEL, G.W.F. Estética. O sistema das artes. São Paulo: Martins Fontes, 1997: 34-42.

2 Essa consideração se deve a análise feita por Foster acerca de determinadas obras de Richard Serra a partir da década de 1990 destinadas a condição de monumentos. Ao comentar sobre Gravity (1993), feita para o Holocaust Memorial Museum em Washington, ele afirma: “[...] Gravity enfatiza o peso que também adquire um sentido espiritual. Gravity é um enorme plano que desce do Pavilhão das Testemunhas no Museu do Holocausto até o andar de baixo; o ícone psicológico aqui não é uma ponte [como em outra obra sua, The Drowned and the Saved], mas uma escada, que possui associações simbólicas próprias. Esse plano escalonado representa uma descida ou uma subida? Expressa gravidade ou graça? Embora o movimento esteja implicado pelos degraus, também é detido pelo plano, e de tal maneira que as oposições entre descida e subida, gravidade e graça parecem suspensas (outra forma simbólica também está presente aqui: o muro memorial). Peças como Gravity e The Drowned and the Saved indicam uma mudança parcial de uma paralaxe entre sujeito e local para uma imobilização do espectador diante da obra". FOSTER, H. O complexo arte-arquitetura. São Paulo: Cosac Naify, 2015: 186. 
moderno (e houve muitos, mesmo depois do modernismo) - afinal, soaria antitético o encontro entre essa forma "pura" e uma retórica "narrativa" - ele foi suficientemente onipresente para não só estender uma lógica de presentificação da memória, como ter sido praticado e se multiplicar. Não exageraria dizer que o monumento físico, um objeto no espaço, mesmo quando inscrito em conceitos como campo ampliado, site-specific e não lugar, perdurou como o último esforço da modernidade ocidental de denotar e associar imperativamente conteúdos a formas plásticas criadas, ao implicar que a memória precisa ser realocada em outra entidade demonstrativa, auto-evidente e visivelmente artística (isto é, fruto de uma notada "invenção" artística transformadora, algo com a assinatura indiscutível do artista - um objeto construído artisticamente, em suma) quase como um fetiche ${ }^{3}$.

Mas o exercício de exumar modernidade e monumento a partir do que já sabemos deles, talvez não nos acrescente muita coisa. Há um outro elo, creio que menos explorado e digno de interesse: como uma teoria da forma autônoma vai ao encontro da conformação freudiana do trabalho de luto? Em outras palavras, estamos diante de uma nova equação entre o que é a decisão de uma memória e o mecanismo segundo a qual ela existe em um espaço e uma experiência públicas, pois necessita-se problematizar diferentes estratos temporais no cotidiano: isso vai da fusão entre o luto pessoal e o coletivo, assim como sua duração (ela pode se esgotar?). No entanto, é a dimensão social do evento a ser trabalhado que inscreve a particularidade necessária ao monumento: ele sempre estará ali para indicar que o resultado no luto não é (nem poderia ser) o esquecimento,

3 Essa observação pretende lembrar que há outros modos segundo os quais a memória é trabalhada sem depender exclusivamente da confecção de uma "obra" plasticamente confeccionada por um artista ou sob sua supervisão. É o imperativo da "obra" que eu denomino de "ocidental", ou melhor, ele chega a nós por meio da narrativa ocidental da história da arte universal. Recorro, para tanto, ao trabalho L'arbre de l'oublier, de Paulo Nazareth, no qual ele volteia 437 a Árvore do Esquecimento, ao redor da qual os homens a serem escravizados no Brasil precisavam dar sete voltas em um ritual de apagamento da lembrança. Para a performance e seus detalhes, ver: http://site.videobrasil.org.br/ acervo/obras/obra/1801794 (acessado em 08/04/2010). Não quero reduzir minha discussão a uma oposição formalismo x pós-formalismo, porém indicar tão somente que existem modos de monumentalidade e de memória que não dependem da construção de uma outra entidade física, de mais um objeto projetado para perfazerem seu discurso. Evidentemente isso pode ser estendido, se admitirmos a apropriação como método, mas, no momento, a discussão enfoca a construção como um dispositivo essencialmente moderno - e, visto desse ângulo, admito que as operações estruturadas na invenção de uma forma por uma transformação plástica da matéria implicam um vestígio formalista; daí estender livremente o termo "moderno" para elas, mesmo que não aplicável de maneira literal. 
mas uma certa superação ou, melhor, a renegociação constante, o reequilíbrio e reestruturação perante o trauma, quando "o respeito pela realidade tem a vitória", na expressão de Freud (a resposta reacionária a isso é a destruição como campanha orquestrada de aniquilamento, de negação da existência de outrem que perturbou a ordem atávica - um exemplo brasileiro de hoje: o ritual macho man de destruir as placas com o nome de Marielle Franco, como perduração extremista do prazer de ofender e desqualificar post-mortem). Ele assinala o luto, mas põe em suspenso seu prolongamento indefinido. Aqui temos, portanto, uma de nossas questões cruciais: o monumento realmente restituiria uma normalidade ao espaço de sua ativação? A resposta não é simples: em primeiro lugar, porque ele sempre (seja com função celebratória, seja como expiação, seja como reflexão crítica) promove uma intervenção, ou seja, ele descontinua uma dinâmica de funcionamento segundo a qual o lugar existira; este, ao ser ressignificado, emana continuamente a tensão entre o que fora, o que foi e o que passa a ser após sua presença; por outro lado ele também é uma admoestação aos presentes de que a vida precisa seguir, cabendo-lhe (ao monumento) dizer-nos o que devemos mudar (por essa razão soa um tanto insólito alguém cogitar em posar para uma foto, ainda mais informal ou sorridente, ao lado dele, como testemunhamos com alguns turistas ${ }^{5}$ ); o monumento moderno pressupõe a experiência trágica, pois a tragédia causou as cicatrizes do século. Ele precisa, num lance duplo, reconquistar um cotidiano sem abrir mão de assombra-lo.

Como o luto é formalizado? Se assumirmos esta última pergunta como aquela capaz de desenhar um novo ângulo sobre a operação moderna do monumento, perceberemos, inclusive, um deslocamento entre como o espectador existe em relação ao monumento modernista e aquele outro empreendido desde os anos 1970.

4 FREUD, S. Trauer und Melancholie. In: Gesammelte Werke, Bande 10: Werke aus des Jähren 1913-1917. Londres : Imago, 1946, 430. Vali-me também da versão em inglês para os trechos subsquentes do mesmo ensaio. Mourning and Melancholy. In: The Standard edition of the complete psychological Works of Sigmund Freud, v. XIV. Londres: The Hogarth Press and the Institute of Psychoanalysis, 1953-1974, 244. Num tom autoindulgente, o autor do presente ensaio lamenta não ter podido recorrer a tradução em português do texto (o que seria o desejável), uma vez que ele foi escrito e finalizado durante o período de quarentena.

5 Mesmo sem legendas, uma reportagem sobre o "uso" do monumento pela maioria dos visitantes é auto-evidente: https://www.youtube.com/watch?v=6U 95W6Tnzk (acessado em 08/04/2020) 
A proposta desse ensaio é encaminhar tal questão, recorrendo a uma sequência de exemplos que têm em comum a resistência ao nazismo no século XX. Alguns deles, ao serem erigidos, logo são vandalizados em ato; outros surgem perante a urgência de reiterar as camadas recobertas sobre onde pousam; cronologicamente falando, o primeiro grupo consiste em realizações empreendidas no Entre-Guerras; o segundo, corresponde ao final do século $X X$, quando entra em jogo saber que tipo de memória será legada daquela era que, nas palavras de Victor Hugo, profetizavam "l'abîme: on ne sait quoi de terrible qu'y gronde" ("o abismo: não sabemos o quê de terrível aí ressoa $\left.{ }^{6 "}\right)$. Nomeando nossos estudos de caso, temos o Monumento aos tombados de março, de Walter Gropius; o Monumento a Rosa Luxemburgo e Karl Liebknecht, de Mies van der Rohe; o Memorial aos judeus austríacos vítimas da Schoah (também conhecido como Nameless Library), de Rachel Whiteread e o Monumento aos judeus mortos na Europa, de Peter Eisenman.

\section{O ponto de vista e de espelhamento}

A atenuação ou supressão do pedestal, alterando a relação entre monumento e espectador, ainda que frequente a partir do século $X X$, não é uma invenção sua. Dois exemplos célebres remontam a alguns momentos decisivos da modernidade: o Monumento fúnebre a Maria Cristina da Áustria, de Antonio Canova (executado entre 1798 e 1805) e o projeto de Auguste Rodin para os Burgueses de Calais (1889). Em ambos pressupõe-se uma intersecção entre a implantação do grupo escultórico e o espaço de existência e circulação do espectador, isto é, uma estrutura de projeção do último no primeiro, cuja ausência precisa ser reativada. Mesmo considerado o gradil de separação e a sua frontalidade (Canova), o espectador partilha estética- e filosoficamente o ritmo do cortejo em procissão: a morte que amealha a todos, indiferente a idade, nosso ingresso visual nas sombras do portão da pirâmide, mergulhando-nos no nada e no vazio. O movimento visual da pirâmide, elevando-se do mundo profano para a eternidade (e, por evocação, a atemporalidade milenar dos originais egípcios), não deixa de ser também uma metáfora de dupla desmaterialização: se as trevas aludem a desintegração do corpo - o esvair-se, a escuridão como extinção 
do ser, a luz que banha o conjunto (mas não pode atravessar sua superfície, reforçando o sentimento de escuridão total trazida pela morte) e sua literal redução corpórea (tentando me explicar melhor, há menos matéria física na base do que no topo, diferindo do que seria a simetria de um quadrado) fazem o contraponto ao seu outro aspecto: o da passagem da vida para a morte como libertação da alma ao corpo que lhe prenderia. Nesse sentido, a situação do monumento é enfática: convoca a condição humana, mas ao mesmo tempo preserva a distância entre princesa e plebeu, assim como entre o mundo do vivo e a contemplação do além. Em suma, ele aproxima e regula distância, o que, a título de comparação, diferencia-se da intenção original de Rodin, ao querer implantar as estátuas de seus burgueses diretamente no chão (ou pelo menos, numa base mínima), fazendo-os não só ocuparem o território da cidade, mas estarem entre nós (e vice-versa). De certo modo, eles, ao acentuarem sua presença objetual - pois estão no mesmo espaço público secular de todas as outras coisas ou pessoas (a igreja onde se encontra o cenotáfio de Canova também é um espaço público, contudo, revestido de uma atmosfera especial, da ordem do sagrado), e se me permitirem uma peroração, parafraseiam uma afirmação de Mies van der Rohe (que mencionarei adiante): quando se trata de um grupo escultórico de burgueses, então eles devem ser instalados onde o burguês existe, na rua - atestam uma outra ação do monumento sobre o real, a qual nós e ele nos atravessaríamos.

Essa lógica, que entre o final do século XIX e as primeiras décadas do século XX resulta no divórcio entre escultura e estatuária, dando margem para a emancipação da primeira, se infiltraria - somada a toda uma investida sobre formas geométricas reduzidas, tidas como correspondentes de valores universais - numa nova configuração do monumento modernista. Ele, formalmente falando, é uma apologia humanista ao gesto construtivo primeiro; sua aparente elementaridade, não por acaso, carrega consigo a memória de obeliscos e dos sistemas ancestrais de sustentação e apoio (primeiros registros humanos da fabricação da consciência de um "além"), afora um imputado espírito transistórico e transcultural. Ele assume uma retórica da forma, e não uma retórica aposta a forma (incrustrada ela). Contudo, essa indicação almeja, em nosso caso, reconduzir a nossa outra questão (como se dá forma ao luto?) em especial quando, estreitando o foco, temos que investigar qual margem especulativa adere esse sentimento à forma abstrata. Desdobrando: como ela afirma, dentro desse contexto, seu entrar no mundo para falar do pós-mundo e conectá-lo a nós, imersos numa vida materialista típica do século XX? 
Uma primeira hipótese de trabalho, ainda tributária a uma abordagem formalista, seria afirmar que a adoção de uma linguagem não-objetiva permite se amoldar a uma nova concepção filosófica da morte ao tirar proveito de seu potencial de inovação discursiva e igualmente de causar estranhamento (a morte é tão estranha e desafiadora quanto essas formas inusitadas da nova arte). Ainda que atravessemos uma rota pavimentada pela presunção, ela tem sua plausibilidade. No anedotário da história da arte e da arquitetura consta o episódio do riso desabonador de Mies van der Rohe, ao ouvir de um de seus interlocutores a descrição inicial do monumento a Liebknecht e Luxembrugo (logo depois disso ele desenvolveria o projeto erguido em 1926), uma proposta recheada de influências de Rodin e ordens clássicas. Mies sentencia que aquele programa estilístico resultaria em um "belo monumento para um banqueiro". A decisão por uma outra concepção - replicando, ao seu modo, a diretriz de Mayakovsky de uma arte revolucionária preconizar uma forma igualmente revolucionária - deixava claro que a figuração de mortes que por metonímia (ou efetivamente) aludiam as multidões e aos conflitos civis imediatos ao primeiro pós-guerra não deveriam reproduzir uma concepção contemplativa classista e anacrônica de figuras mitológicas (como aquelas de Canova, mesmo em seu paganismo historicista), além de trabalha-la sob um novo tipo e dimensão de impacto (digamos que no mundo moderno morre-se sem providência divina nem metafísica; ao contrário, ela se assume cruamente física). O monumento moderno inaugura para si uma dimensão imagética de poder semelhante ao do cartaz. Do ponto de vista teórico, tal atitude se alimentava não menos do debate promovido pela geração imediatamente anterior, ilustrada no ensaio $O$ culto moderno dos monumentos - seu sentido e sua constituição (Der Moderne Denkmalkutus - sein Wesen und Entstehung), de Aloïs Riegl, publicado em 1903. Riegl não necessariamente se interessa por monumentos modernistas. Não obstante, em determinada passagem ele comenta:

7 "[...] o senhor Fuchs [Eduard Fuchs, historiador da arte, colecionador e membro do Partido Comunista Alemão] disse que queria nos mostrar algo [...] uma fotografia de uma maquete para um monumento a Karl Liebknecht e Rosa Luxemburgo. Fuchs se ocupava de buscar um projeto para um monumento comemorativo dedicado aos mártires da desafortunada sublevação de 1919 levada a cabo pela Liga Espartaquista. Wilhelm Pieck, dirigente do partido, propusera fazer esse monumento e, em julho de 1925, afirmava ter realizado uma maquete, cujo elemento central era uma escultura de Auguste Rodin [...] com colunas e medalhões dóricos de Luxemburgo e Liebknecht [...] Quando os vi, comecei a rir e lhe disse [a Fuchs] que seria um belo monumento para um banqueiro". SCHULZE, F., WINDHORST, E. Mies van der Rohe: una biografía crítica. Barcelona: Reverte, 2017 (edição digital Kindle). 
Será que este valor artístico [do monumento] está dado no passado tão objetivamente como o histórico, de tal modo que constitua uma parte essencial e independente do elemento histórico do conceito de monumento? Ou é um valor subjetivo, inventado pelo moderno sujeito contemplativo, sujeito ao seu bel-prazer e como ele cambiando, não tendo cabimento, neste caso, no conceito de monumento como uma obra com valor de memória?[...] [V]igora até o século XIX a tese de que existira um cânone artístico absoluto, um ideal artístico objetivo, absolutamente válido, que todos os artistas se esforçavam por atingir, mas que dificilmente poderia ser completamente alcançado [...]. O século XIX eliminou quase todos os restantes períodos artísticos conhecidos na sua significação independente; mas nem por isso abdicou da crença num ideal artístico objetivo. Só por volta do princípio do século XX é que se chegou ao ponto de extrair a consequência necessária da noção de evolução histórica e de declarar toda a criação artística pretérita como irrevogavelmente passada para nós e, por isso, não sendo de modo nenhum decisiva para a formação de um ponto de vista canônico. Se não nos confinarmos, contudo, à apreciação artística das formas modernas, mas avaliamos também as antigas por mor de sua concepção, forma e cores, e às vezes até as julgamos superior às modernas, isto (abstraindo do fator estético sempre presente no interesse histórico) deve ser compreendido no sentido de que certas obras de arte antiga correspondem, ainda que não no todo, certamente, no entanto, em certos pontos à vontade artística moderna. E é precisamente a aparência dessas partes concordantes da plástica [Folie] daquelas obras antigas que, confrontadas, exercem sobre nós, modernos tamanho efeito, que jamais poderá se desenvolver numa obra de arte moderna, cuja plástica [Folie] precisa se passar por algo necessário. Segundo os conceitos atuais, não existe a partir daí nenhuma obra de arte absoluta, mas somente uma [obra de arte] relativa, moderna ${ }^{8}$.

Mas essas são premissas, e não podemos escapar de nosso problema: a encenação da "morte segundo o modernismo". Dito isso, temos uma chave para acessar o Monumento aos tombados em março (Denkmal für die Märzgefallenen), de Walter Gropius, inaugurado em Weimar no $1^{\circ}$ de maio de 1922 (Fig. 2). Ele celebra os trabalhadores mortos pelos soldados de extrema direita envolvidos no Kapp Putsch (tentativa de golpe de Estado conduzida pelo jornalista, funcionário público e político reacionário Wolfgang Kapp junto com o general Walther von Lüttwitz), em 1920. Nas palavras do arquiteto, a escultura em concreto visualizava o "clarão de um raio irrompendo do chão da sepultura como emblema do espírito vivo" ("Blitzstrahl aus dem Grabesboden als Wahrzeichen des lebendingen Geistes"). Se a plasticidade do concreto imediatamente celebra os materiais modernos contrapondo-se à nobreza daqueles históricos - reiterando nisso questões

8 RIEGL, A. Der Moderne Denkmalkultus. Sein Wesen und seine Entstehung. Viena e Leipzig: W. Braumüller, 1903, 4-5. Vali-me nesse trecho das traduções em português ( $O$ culto moderno dos monumentos e outros escritos. Lisboa: Edições 70, 2016, edição digital) e inglês (The Modern Cult of Monuments. Its character and its origin. In: Oppositions. Nova York: Rizzoli / The Institute for Architecture and Urban Studies, n. 25, outono 1982 22-23), com mudanças pontuais em algumas partes. 
não só de custo, mas da materialização da metáfora da luta de classes - pois desenvolve movimentos, torções e balanços nem sempre muito viáveis às técnicas tradicionais, a forma dá corpo ao último fulgor explosivo da vida ("Mais luz!", durante gerações tida como as palavras finais de Goethe), um derradeiro gesto enérgico como celebração de uma resistência iluminista. O raio, que liga terra e céu, perfaz uma sobrevida (Nachleben, para indicar um termo corrente no atual vocabulário teórico), ao rotacionar a horizontalidade e retorno à terra dos mortos para a verticalidade bípede e ativa dos vivos. Pensando sob o viés material, o concreto simboliza e realça a transformação da matéria orgânica em inorgânica, porém durável. Morrer é extinguir-se, mas não esquecer ou deixar para trás, nem ausentar-se, e o monumento intensifica sua força totêmica graças a essa verticalidade. A base - mínima e se distendendo quase como um piso -, cria um passeio em torno dos volumes, estruturados em variações do tema piramidal, de força expressionista e espacialidade cubista, obrigando-nos a testemunhar quem jaz, pois esses mortos ainda falam e não abandonaram por completo o território dos vivos; ao contrário, nos fazem adentrar nesse além niilista. Não se trata exatamente de um culto (ainda que haja respeito) aos mortos, mas uma advertência a nossa responsabilidade de intervir na vida. O monumento vai ao encontro do olhar, não o obriga a esticar o pescoço submissamente (um gesto de resignada melancolia romântica - "erguer-se para o céu cruelmente azul e irônico, / a cabeça emergir do pescoço convulso, / como se a Deus lançasse um desafio agônico ${ }^{9 \prime}$ ), uma relação substancialmente diferente daquela articuladora, por exemplo, do Monumento aos tombados na Guerra Franco-Prussiana (por mais que ambos trabalhem a elevação numa composição piramidal), com seu escalonamento e o recurso rumo a alegoria oficial, produzindo entre os dois o deslocamento da metáfora consoladora para a instigante. No grupo escultórico do conflito do século XIX, a separação entre quem vive e quem não existe é imprescindível para sua economia mítica da reverência distanciada. $O$ fato de Gropius ter usado um misto de expressionismo e de pós-cubismo (ele mesmo fora vítima do Shell schok, um "equivalente masculino" da histeria diagnosticado nos veteranos da I Guerra), como linguagem atual de escândalo e corte com os protocolos de uma civilização que morrera, do espírito de época de "uma geração que cresceu para descobrir que todos os deuses morreram, todas as guerras haviam sido combatidas, toda fé no homem 
Figura 2

Walter Gropius. Monumento aos tombados em março de 1920, 1922. Weimar estava abalada ${ }^{10 \prime}$, patenteava que a fronteira social entre vivos, semi-vivos, mutilados, inválidos e mortos enunciara novos contornos tanto espirituais quanto cotidianos, pois essa legião agora vivia promíscua entre ruas, cafés, bordéis, sanatórios e gabinetes, como relembram as pinturas da Neue Sachlichkeit de Otto Dix e Max Beckmann. Seu choque visual contrasta com o entorno vazio de sua instalação (ao menos nas fotos da época) no cemitério histórico de Weimar, tornando o discurso do monumento incontornável: o "passado" não está pacificado nem repousa, mas está entre nós.

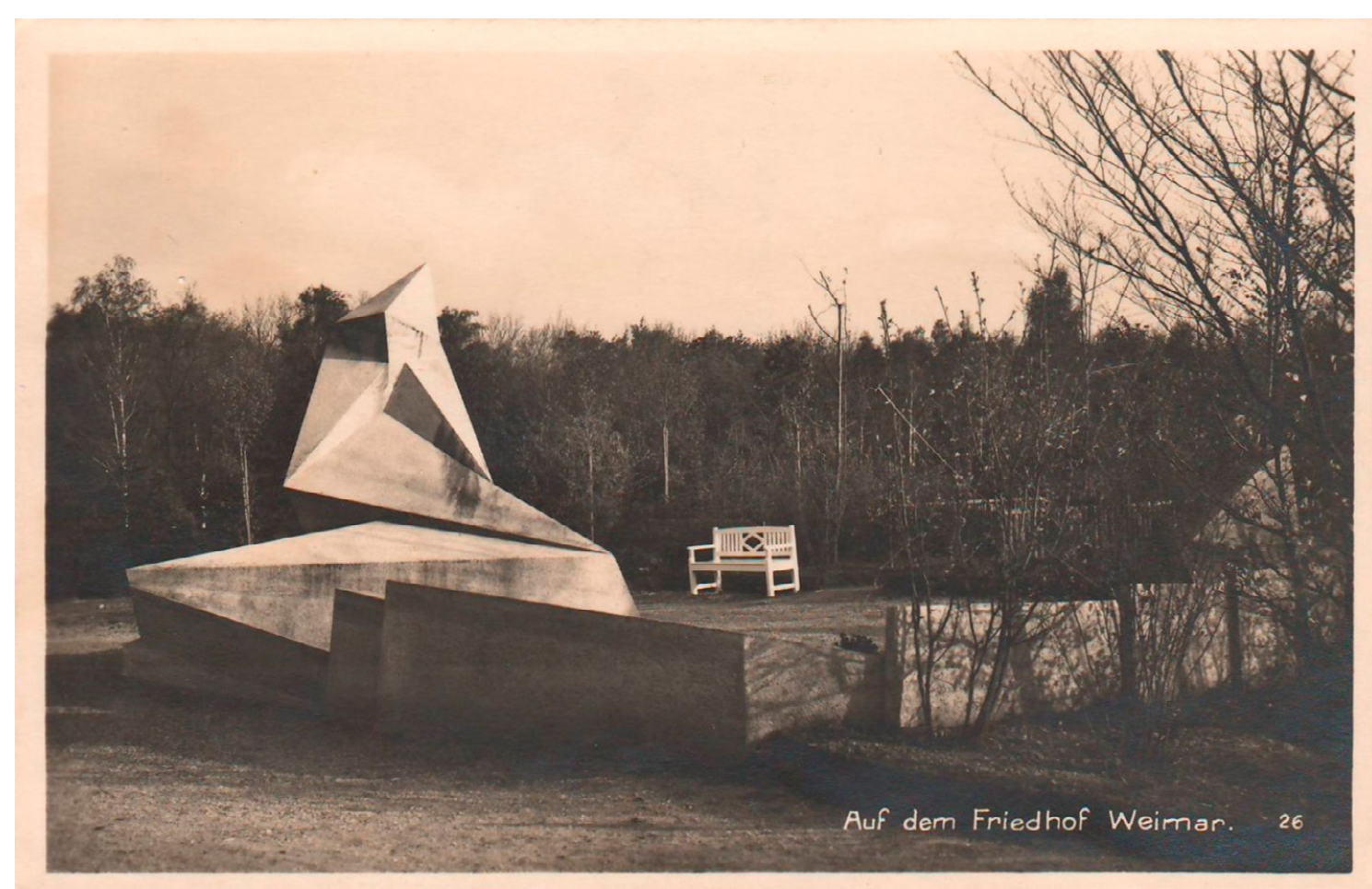

\section{O vestígio}

Chegou o dia da revolução. [...] O antigo acabou. Karl Liebknecht, 10 de novembro de 1918

O Monumento Moderno admite também uma transformação semântica da matéria aparentemente inalterada em sua corporeidade, diferente do

10 FITZGERALD, F.S. This side of paradise. Londres : Penguin, 1996, 260 (tradução em português: Este lado do paraíso. São Paulo: Cosac Naify, 2003, 329). 
uso do concreto por Gropius (e, por mais improvável que pareça, há uma conexão razoável entre a abordagem racionalista da arquitetura e a apropriação dadá ${ }^{11}$ ). Prova disso é a obra dedicada a Rosa Luxembrugo e Karl Liebknecht (1926), desenhada por Mies van der Rohe (fig. 3). Ela faz a elegia tanto das duas lideranças (vinculadas ao partido comunista), protagonistas do estabelecimento do que seria a República de Weimar, quanto das vítimas dos distúrbios no parlamento alemão em 1920 e dos trabaIhadores mortos. Em 1935, o monumento foi arrasado até o chão por militantes nazistas, jamais sendo reconstruído (diferentemente do projeto de Gropius; da obra de Mies, hoje há apenas uma placa em sua referência, uma espécie de memorial ao monumento).

Figura 3

Mies van der Rohe

Monumento às vítimas da Revolução (Também conhecido por Monumento à Revolução de Novembro e Monumento a Rosa Luxemburgo e Karl Liebknecht, 1926. Berlim (destruído). Imagem publicada na Revista Kunst und Künstler, n. 7, 1927.

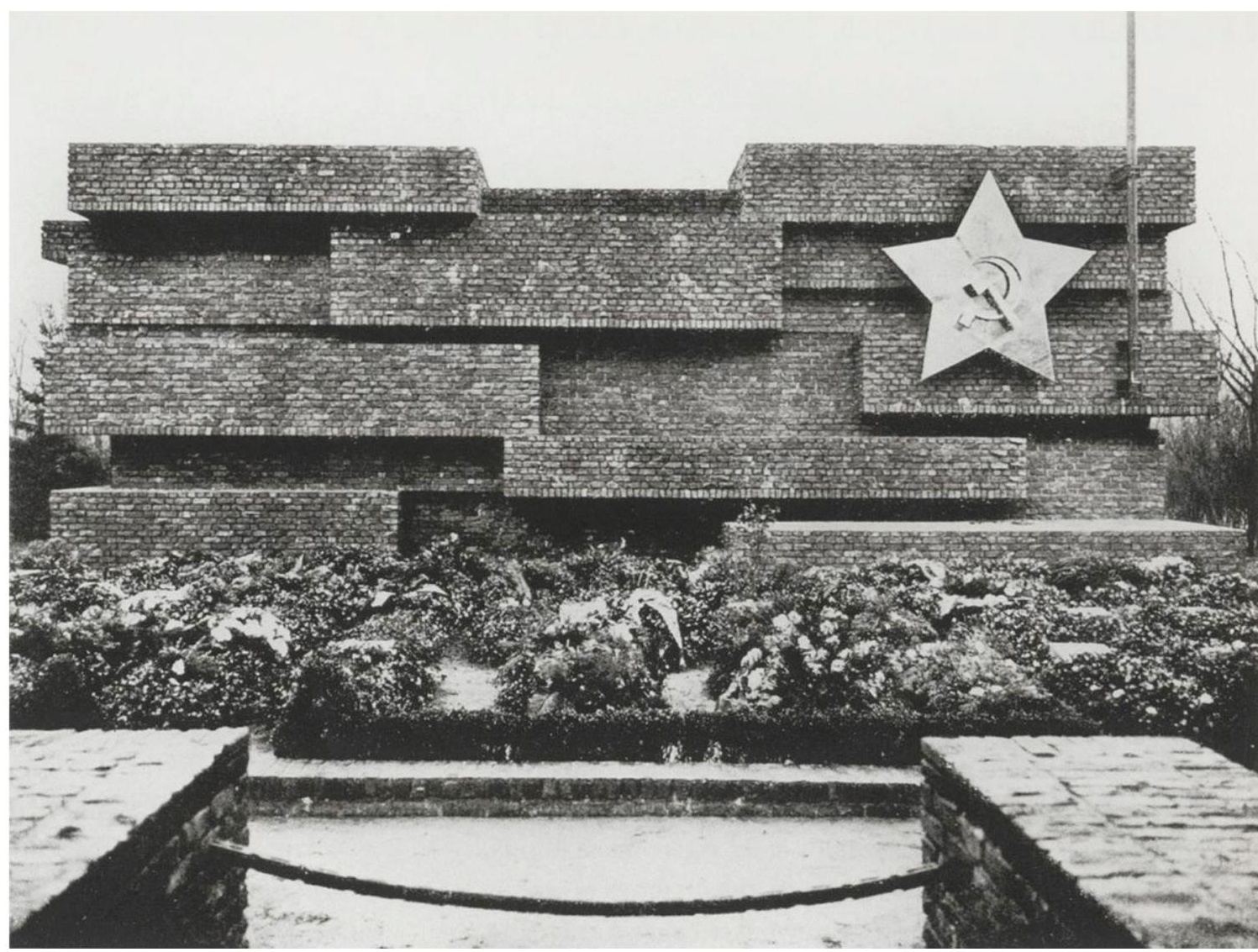

11 Entre 1923 e 1926, Mies van der Rohe esteve envolvido com a revista G - Material zur elementaren Gestaltung, editada por Hans Richter e Werner Gräff, que divulgava artigos sobre as diversas correntes de vanguarda na Europa. Há, não menos, o famoso registro fotográfico do arquiteto visitando a Primeira Feira Internacional Dada, ocorrida em Berlim em 1920. 
Quando indico a ressignificação da matéria, tenho em mente a "tautologia" de Mies (era a ela que me referia, quando fiz a paráfrase a instalação dos burgueses de Rodin) ao comentar aquela primeira versão frustrada do monumento pretendido, logo em seguida assumindo a tarefa de substitui-la. Pouco antes disso, ao ironizar o desafortunado anteprojeto antecessor, perguntado sobre o que ele faria, limitou-se a responder a Karl Fuchs, seu interlocutor na ocasião: "Disse-lhe que não tinha a menor ideia [...] mas como quase todas essas pessoas eram fuziladas diante de um muro, um muro de tijolos seria o que eu construiria ${ }^{12 "}$ e, segundo o próprio arquiteto, quatro dias depois ele apresentaria os croquis desse "muro".

O "muro" erguido era, na verdade, um entroncamento de volumes de tijolos clínquer em forma de paralelepípedos alinhados, coletados em diversos canteiros de escombros. Podiam não ser exatamente aqueles cravejados de balas, mas eles, ali rearranjados nesse novo contexto, operavam a transfiguração sem passarem por nenhum outro gesto sublimatório senão o empilhamento (Gropius modelara seu raio a partir do concreto informe, num resquício apologético da divindade inerente à "criação"). Os tijolos, anônimos, seriais e com suas lascas escarificadas, evocavam não menos o cimento social do proletariado e a escala repetida das multidões - são unidades de trabalho, mas igualmente cicatrizes ${ }^{13}$. E, assim como em Gropius, há uma dupla operação pós-cubista, graças a ela distendendo-se o processo entre imanência e espelhamento acionado pelo objeto. A primeira parte consiste na contaminação com o espaço "real", mais uma vez através da implantação direta no solo, ocupando o mesmo terreno de seus espectadores sem recorrer a hierarquização do pedestal. Malgrado o contexto de um cemitério, a princípio um entorno ermo, o objeto está tão atravessado pelo mundo real quanto todas as energias que se entrecortam na rua (como nas colagens em dupla exposição tão em voga no cinema de vanguarda da época). Por mais que seja formalmente diferenciado, o monumento pertence ao terreno da vida em comum e a ele se comunica diretamente. Se sua forma inusual - para monumentos fúnebres - poderia a

\section{SCHULZ. Op. cit.}

13 Para uma discussão a respeito do monumento de Mies, consultar: BUENO, G. O retorno de um monumento. A história do Monumento a Rosa Luxemburgo e Karl Liebknecht, de Mies van der Rohe; aspectos de sua recepção historiográfica no imediato Pós-Guerra. In: BRANDÃO, A., TATSCH, F., DRIEN, M. (Org.). Política(s) na História da Arte: redes, contextos e discursos de mudança. 1ed.São Paulo: Programa de Pós-Graduação em História da Arte UNIFESP, 2017, v. 1, p. 211-221. 
princípio causar de novo perturbação (e não é apenas a sua destinação, assim como no caso de Gropius, que convocaria a ira nazista, mas sua plástica "degenerada"), isso apenas confirma a nova configuração, sentido e escala da morte "moderna" apontada acima, bastando pensa-los lado a lado com os inúmeros cemitérios de tumbas enfileiradas dedicados aos soldados caídos na I Guerra (que se tornariam protótipo para todos aqueles que lhes sucederam). Estamos falando dessa morte coletiva, não mais individualizada ou condensada e sublimada na alegoria mitológica, como na antiga arte funerária. No que concerne o espelhamento, o que em Rodin era o "duplo" das estátuas, em Gropius o passeio suscitado pela extensão e rotação, no monumento de Mies, são a ocupação e a analogia que entram em ação.

Começarei pela ocupação, mais evidente. Novamente distinguindo-se da posição contemplativa, o monumento - que, insisto, faz os mortos permanecerem no espaço da vida, em função daquela mediação mínima entre os mundos, todos repousando sobre o mesmo chão (que o nazismo em breve transformaria no infame Boden, criticamente tematizado depois por Peter Eisenman) - convoca seus interlocutores a habita-lo. Provam-no as fotos de época com celebrações cívicas: há participantes em frente, acima, em diversas partes (Fig. 1) , ecoando o dístico "Eu sou, eu era, eu serei" (Ich bin, ich war, ich werde sein), atribuídos ao último discurso de Luxemburgo citando o verso de Die Revolution, poema de 1851 do agitador político Ferdinand Freiligrath: o que seria uma profanação, aqui se converte em ativação; a chama do heroísmo só perdura se sua lição reverbera e se propaga na vida comum. Daí a ocupação ser essa espécie de estar com propiciada pelo estar ali, não apenas de frente, mas em meio.

A analogia, apesar de menos óbvia, é poeticamente contundente. Seu monumento é uma casa para os mortos que, até certo ponto, se alinha as hipotéticas residências modernistas para o futuro (o que implica mais uma vez nessa nova modalidade segundo a qual a morte responde ao cotidiano e seus traumas), ambas curiosamente proselitistas de uma libertação. Explico-me: na mesma época em que desenha o memorial, Mies se ocupa de vários projetos explorando a técnica de emprego de tijolos que ele aprendera nos Países Baixos, como se nota nas casas Wolf (Gubin, 192527), Esters e Lange (Krefeld, 1927-1930), além de um célebre projeto não-realizado (hoje tomado muito mais como hipotético) para uma Casa de campo de tijolos (1923-24). Não diminuirei aqui a evidência de que o arquiteto testava métodos, materiais e questões estéticas, o que permitiria ler o monumento somente como uma das ocasiões das quais dispôs. Ainda assim, considerando sua sentença sobre o muro dos fuzilados, sua decisão 
indicava naquele caso - apesar de sua famosa e dúbia posição "apolítica" -, não se tratar unicamente de mera questão de prática profissional. 0 "muro" no monumento é menos o obstáculo imposto outrora pelo pedestal do que essa casa a ser "visitada" - o invólucro que acolhe os que partiram e recebe aqueles que os conjuram - por aqueles que (ainda) estão entre nós; entre as casas dos mortos e dos vivos, no seu contínuo visual, se desenha uma simetria. Que a obra tenha sido arrasada - que morra de novo - é sintomático da perpetração do segundo assassinato pelos nazistas àqueles já defuntos (uma questão colocada sob outro ângulo no memorial de Rachel Whiteread). Ressalto, não obstante, que a metáfora da casa dos mortos entremeada a casa dos vivos aponta para esse outro nível de espeIhamento e presença a marcar a simbolização da memória, essa categoria paradigmática examinada pela psicanálise, pela filosofia (Bergson) e pela sociologia (Durkheim) naquela primeira metade do século XX.

Aqui eu me permito um salto abrupto para o final do século $X X$, mas não gostaria que ele fosse visto como despropositado. Nas primeiras décadas daquele período discutivelmente descrito como o "fim da história", vivia-se entre o dever retrospectivo do mais curto dos séculos e a ansiedade com a virada rumo aos anos 2000, em um ambiente de balanço e prestação de contas com o passado e os mitos que o forjaram. Sob tais circunstâncias podemos examinar os projetos de Rachel Whiteread em Viena e Peter Eisenman em Berlim, inclusive no que eles investem uma abordagem contemporânea ao território da cidade e a especificidade do lugar (por mais que reitere o que disse no início: não obstante esses deslocamentos, eles ainda vivenciam o objeto "monumento" como uma categoria moderna).

Nos dois casos, retoma-se o dispositivo moderno da repetição como anonimato e multidão, mas o vetor muda, pois a série corresponde a personagens diferentes, separados pelo antes e depois da II Guerra e do Holocausto; também altera-se o sentido da implantação, uma vez que agora historicidade e especificidade se fundem. Soluções como a de Gropius e Mies, por mais que assinalassem o ingresso e o uso no espaço real, ocupavam áreas públicas, porém isoladas (o monumento estaria até certo ponto protegido no cemitério e não no fervilhar da cidade, mesmo que ela ingresse ali) elas se equilibram entre o mundo cru e um espaço tratado à semelhança do modelo abstrato da pintura: inscrevem-se no terreno concreto, mas este último em si, conserva uma abordagem universalista (aquela ubiquidade atribuída a autonomia da escultura moderna): descontado algum exagero de minha parte, seriam monumentos que poderiam ter sido erguidos em 


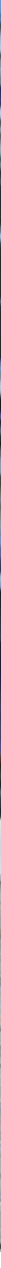

Figura 4

Rachel Whiteread. Memorial aos 65.000 austríacos judeus vítimas da Shoah, 2000. $3,8 \times 7 \times 10 \mathrm{~m}$, Viena.

Foto: Hans Peter Schaeffer (disponível em: https://commons.wikimedia.org/ wiki/File:Rachel_whitereadwien_holocaust_mahnmal_ wien_judenplatz.jpg) qualquer outro canto do planeta ${ }^{14}$. Tanto Whiteread quanto Eisenman lidam com chãos imantados pelo trauma da história - cenários de seus eventos -, cuja pulsão segue latente e, ao neles se instaurar esse objeto de luto, reativam na ordem do cotidiano o passado problemático. Eles não podem ser movidos ou adaptados para outro lugar. Em outras palavras, estão lá para não se esquecer que, algumas décadas antes, por ali passaram a procissão e o cortejo da barbárie. O crime pavimentou aqueles caminhos (uso acusatoriamente o termo presente em Heiddeger). O projeto de Whiteread (fig. 4) é construído na Judenplatz, uma área sob a qual se encontram os vestígios (no subsolo) de uma sinagoga medieval incendiada em 1420, contrastando ainda com a Jordanhaus, uma das edificações mais antigas da cidade, em cuja fachada há um medalhão em relevo, no qual consta, desde o século XV, uma inscrição antissemita (portanto "patrimonializada"). Até sua inauguração, o memorial enfrentou polêmicas de diferentes naturezas, de sua interferência na estética dos arredores a oposição por mais um monumento (nesse caso exclusivamente dedicado aos judeus), quando, ali perto, já havia outro para as vítimas do nazismo e do fascismo.

14 Uma demonstração indireta disso foi sua releitura pela artista croata Sanja Ivekovic, em 2013, ao reproduzir sua forma em uma instalação na documenta 14. 
O memorial é um grande bloco de concreto, cujas paredes são moldagens de lombadas de livros. Como não há nenhuma inscrição neles, evocam simultaneamente a biblioteca (e, por extensão, a contribuição judaica a cultura germânica na qual figuram autores ilustres como Lessing, Winckelmann - mesmo sabida a sua conversão ao catolicismo, Heine, Moses Mendelsohn, Mahler - outro convertido por força maior, Freud), a centralidade do texto e da palavra na cultura judaica, mas, por contraste, os livros e registros de mortos. O tema do livro, ampliando-se o contexto segundo o qual ele ali existe, abre-se para outras interpretações que convocariam, inclusive demais especificidades históricas da cidade. Não seria o livro, afinal, uma das formas de monumento que sobrevive ao indivíduo (a máxima cunhada por Horácio para sua própria poesia em sua terceira ode - Exegi monumentum aere perennius / regalique situ pyramidum altius; Mais perene que o bronze um monumento ergui / Mais alto e régio que as pirâmides $\left.{ }^{15}\right)$ ? Mais além, na história de Viena, em sua análise do monumento, Riegl (que escrevera seu ensaio para refletir parâmetros de preservação do patrimônio da cidade), elenca logo na abertura o escrito como uma de suas formas existentes:

\footnotetext{
Em seu sentido mais antigo e original, compreende-se por monumento uma obra produzida pela mão humana, erigido para uma função específica: preservar sempre vivos e presentes na consciência das gerações futuras os feitos ou o destino de uma pessoa [...] Ele pode ser um monumento artístico ou escrito [Schriftdenkmal] [...]; o principal é que ambas criações estão igualmente unidas entre $\mathrm{si}^{16}$.
}

Essa espécie de anti-pitoresca estela funerária de livros, livros que parecem feitos de cinzas prensadas (impressão suscitada pelo tom do concreto) trazem à tona também a segunda morte: o epistemicídio movido pelo nazismo ao conjugar genocídio com depredação de objetos e documentos, espetacularizado nas infames piras de queimas de livros, como se ali, ao crema-los, simbolicamente se martirizasse novamente por metonímia os seus autores. O memorial - o que revela uma analogia com a desdita do monumento projetado por Mies nos anos 1920 - é também memorial a esse outro patrimônio, o cenotáfio a céu aberto dedicado a uma biblioteca de Alexandria do século XX, em uma cidade maculada por sua má cons-

15 Tradução de Haroldo de Campos.

16 RIEGL, A. Op. Cit.: 1. Quando Riegl se refere aos monumentos escritos (Schriftdenkmal), ele abarca inscrições, documentos e outros patrimônios escritos. 
ciência. As ruínas sob a obra, no subsolo, mais do que preservar, trazem para a cidade aquilo que, soterrado, camuflara, no forjar de uma rotina retomada e que "esquece", o que de fato fora um aniquilamento consentido (aniquilamento deriva do "reduzir a nada"- a nihil). Ainda em paralelo a Mies, o que soaria como outra profanação tumular, reverte-se na sua recuperação, volta para a superfície, obrigando Viena, por outro lado, a lidar com sua cumplicidade e culpa. Por fim, há as portas, que pareceriam abrir, porém estarão sempre seladas; não há interior onde encontrar repouso. É negada a transcendência da portada de Canova, o mergulho silencioso no além está embarreirado, há um bloqueio - bloqueio psicológico, categoria tão examinada pelo precursor da psicanálise ali nascido, de uma sociedade, nessa obstrução que torna corpóreo o fantasma do silenciamento.

Figura 5

Peter Eisenman. Monumento aos judeus da Europa assassinados (Monumento ao Holocausto), 2005. 19.000m2, Berlim. Foto: Alexander Blum. (disponível em: https://commons.wikimedia. org/wiki/File:Memorial_to_the_Murdered_Jews_of_Europeabove.jpg)

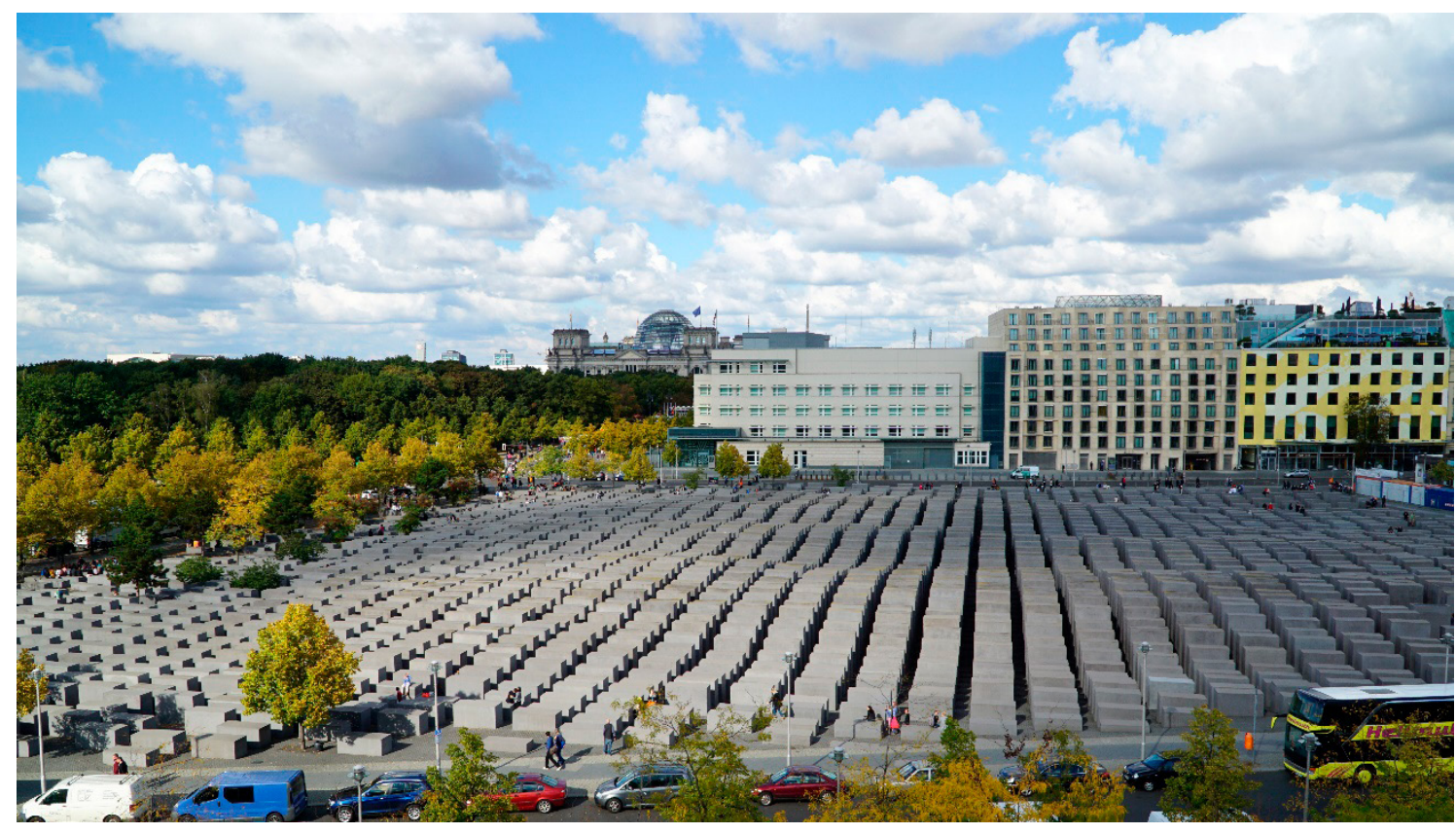

Exumar e desaparecer são relações também intrínsecas ao Memorial aos Judeus Europeus Assassinados (Memorial do Holocausto), de Peter Eisenman, inaugurado em 2005 (projetado em 1998), sob o que se tornara desde o fim da Guerra Fria uma enorme terra de ninguém em pleno centro de Berlim, uma área convidativa para a especulação imobiliária após a reunificação (fig. 5). Ele se instala numa simetria eloquente: tomando como eixo Unter der Linden (a principal artéria no coração da cidade), na qual figura como ponto culminante o Portão de Brandenburgo (marco da Berlim prussiana e da queda do muro em 1989), no lado oposto temos o Reichstag (a sede do parlamento alemão), no qual em 1919 se fundara a república e cujo incêndio em 1933 desaguou na submissão completa da Alemanha a ditadura nazista. Do memorial é possível ver, ao longe, a cú- 
pula do Parlamento, intensificando o sinistro vínculo que os conecta. $O$ projeto implica no deslocamento das pessoas nas vielas dessa metáfora de um cemitério de sepulturas enfileiradas. Eisenman, assim descreve seu partido no desenho:

\begin{abstract}
Esse projeto manifesta a instabilidade inerente ao que parece ser um sistema aqui a grade racional e seu potencial para dissolução no tempo. Ele sugere que, quando um sistema supostamente racional e ordenado cresce demais e fora de proporção ao propósito que intencionara, ele perde contato com a razão humana. Ele começa então a revelar os distúrbios inatos e o potencial para o caos de todos os sistemas possuidores de uma aparente ordem. [...]

Nesse monumento, não há meta, nem fim, nem trabalhar o percurso de alguém dentro ou fora. A duração de uma experiência individual dele não garante nenhum entendimento posterior, uma vez que entender o Holocausto é impossível. O tempo do monumento, sua duração - do topo ao chão - está disjunta do tempo da experiência. Nesse contexto, não há nostalgia, não há memória do passado, apenas a memória viva da experiência individual.
\end{abstract}

O que viria a ser essa experiência individual? Apesar de prenhe de turistas, atravessar o caminho entre os blocos é capaz de provocar um desconfortável sentimento oceânico e labiríntico de desorientação (mesmo sendo uma malha tão regular quanto a de Manhattan) e solidão. Não se trata de restituir o pesadelo dos mortos, mas ver-se, em certos momentos engolido pela "aparente ordem" a que o arquiteto se refere (comparativamente, a questão do percurso acontece também no caminho "processional" feito no Museu Judaico de Berlim, de Daniel Liebskind, valendo-se dele para contar a história dos judeus na Alemanha; e, em outro aspecto, que coloca-nos na solidão, nos Vazios - espaços vazios que ele inscreve nos pontos de cruzamento das paredes do edifício, nos quais só se tem do alto uma luz rarefeita em um ambiente de escala assumidamente "desproporcional"). Eisenman, involuntariamente ou não, com a serialidade dos blocos, perfaz uma sinistra elipse da necropolítica do século XX: a mórbida repetição obsessiva da pop e a manipulação das massas nos sistemas totalitários encontram aqui o seu duplo no fordismo do terror. Aquele que faz o percurso, capturado pela estrutura, convive, ao mesmo tempo, com essa experiência materializada no terreno. Eisenman, em outro trecho do memorial descritivo, comenta o partido que tira das ondulações do chão, criando uma zona de instabilidade. No entanto, esses declives desencadeiam, seja no trajeto do caminhante, seja no momento em que ele consegue ver outras pessoas, a imagem da desaparição. Em determinados trechos, os blocos se elevam mais do que outros e gradativamente vemos as pessoas sumirem e nós sermos engolidos (ou emparedados) e também perdidos da vista alheia. No subsolo, tal como na obra de Whiteread, o visitante encontra 
uma sequência de galerias nomeada Lugar da Informação, com os nomes dos cerca de 3 milhões de judeus vítimas do Holocausto (se considerarmos o deslocamento pela superfície de Berlim, o memorial dista a poucos quilômetros da Topografia do terror, um vestígio do muro preservado no qual também é apresentada parte da história recente do país) e a mesma inversão que tensionara o desvelar no presente e o camuflar da reconstrução no tecido urbano.

Para dimensionar esse esfolar semântico do site specific - isto é, de que esse lugar precisa existir ainda como uma espécie de não-lugar (não exatamente no sentido conceituado por Marc Augé, e sim pela noção de heterotopia de Foucault; nesse caso, uma heterotopia que assim se configura ao pôr em questão que tipo de "normalidade" se pode esperar nesse espaço comum) - o cotejo com duas referências da arte contemporânea dos anos 1960-70 são providenciais para uma compreensão de certas estratégias de ocupação aparentemente similares, mas discursivamente diferentes.

De um lado, temos Les deux platôs (ou, as colunas), de Daniel Buren, instalado no pátio do Palais Royal, em Paris. Buren emprega o mesmo sistema de variação de alturas e do visível penetrar de colunas na praça. Porém - e esse é o motivo de trazermos sua obra - enquanto em Buren essas alternâncias se enunciam como uma relação métrica com o espaço, em Eisenman ela se cristaliza como uma teatralização trágica; eu afirmaria que isso denota seu outro princípio de monumentalidade, pois o sistema, apesar de vivenciado fisicamente em ambos, no francês conduz a experiência corpórea a abstração matemática (por mais que seja fenomênica), enquanto em Eisenman, o espelhamento - de impulso semelhante ao de Rodin ou de Mies - protagoniza nosso estar ali como repetição simbólica do passado.

O outro exemplo em diálogo com Eisenman seria o projeto não realizado de Walter De Maria Olympic Mountain Project (1970-71), inicialmente encomendado para os jogos olímpicos de verão de 1972, que previa perfurar uma montanha em Munique com uma coluna oca de 120 metros, encimada por uma plataforma de bronze. A recusa do comitê deixaria claro o incômodo provocado, uma vez que essa montanha em forma de vulcão havia sido construída artificialmente com escombros, remetendo diretamente a esse disfarce de vestígios de um passado a ser enterrado para sempre. Ao desenterrar, Eisenman, assim como Whiteread assumem, portanto, com a visibilidade desse subsolo não só a erupção desse recalque, mas o quanto ele é uma operação histórica a ser problematizada: o apagamento da memória é também uma discussão sobre as manobras posteriores do 
status quo que se empenham em realiza-lo. De Maria escolhe pela instabilidade de ver através. Eisenman e Whiteread, ainda que mediada por uma forma de transição, explicitam pela proximidade escancarada e evidente, o não se permitir não saber, não ter ideia, não querer ver. O "panfletarismo" de ambos, ao reabrir essas escavações-veias, descontada ou não a liberdade poética, ao fim e ao cabo é uma prestação de contas com a cultura em que intervém: para quê poetas em tempos de miséria? Ou para quê poetas depois dos tempos de miséria?

Mas para quê monumentos, quando temos de pé as usinas e os testemunhos reais do horror - os campos de concentração, a casa de Annie Frank as pichações e marcas de balas pelas cidades europeias, as lições dos sobreviventes? O quê eles poderiam dizer (ou não dizer) a mais?

Após discutir como os monumentos dão forma ao luto, fecharia esse ensaio com duas hipóteses do porquê eles parecerem necessários, perante a permanência daqueles testemunhos. Pensando em conjunto os casos do Entre-Guerras e da virada do século XX para o XXI, acredito que adaptar com muita liberdade um termo oriundo de Freud nos dê uma pista: assim sendo, minha primeira hipótese é do monumento executar uma intercessão entre o estranhamento inquietante (Unheimliche) e o que o psicanalista vienense denominaria como objeto catexizado, isto é, um objeto sobre qual se projeta uma determinada energia psíquica ${ }^{17}$, em especial, numa situação de perda, quando "o teste da realidade mostrou que o objeto amado não mais existe e começa a demandar que toda libido seja descartada de todo vínculo a esse objeto ${ }^{18 " . ~ E s s a ~ n o c ̧ a ̃ o ~ p e r p a s s a ~ u m a ~ p a s s a g e m ~ d e ~}$ seu Luto e melancolia, quando o autor analisa seu papel no retorno ao real:

Ademais, o luto normal supera a perda do objeto e igualmente absorve durante
seu estado todas as energias do Ego. Por quê também não se produz nele a con-
dição econômica de uma fase de triunfo após sua expiração? Parece-me impos-
sível responder sem hesitar a essa objeção. A esse respeito, devemos ainda notar
que nunca podemos dizer por meio de quais meios econômicos o luto resolve
sua tarefa. Mas talvez uma conjectura pode auxiliar-nos aqui. Em cada uma das
lembranças ou situações de expectativa, na qual a libido se mostra associada ao
objeto perdido, aproximando a realidade de sua espessura, na qual o objeto não

17 Essa definição foi tomada do verbete "Catexia" (Besetzung) em LAPLANCHE, J., PONTALIS, J.-B. Das Vokabuläre des Psychoanalyse. Frankfurt am Main: Suhrkamp, 1972, 92 (tradução em inglês: The Languaae of Psycho-Analysis. Londres : The Hogarth Press, 1973).

18 FREUD. S. Op.cit. : 430 (tradução inglesa : 244). 
existe mais, o Ego, posto igualmente diante da pergunta se ele quer partilhar desse destino, permite-se - através da soma do prazer narcísico de estar vivo determinar a ruptura de seu vínculo com o objeto aniquilado. Pode-se assim imaginar que essa ruptura é em si tão lenta e progressiva, que, com o fim do trabalho [de luto], a energia nele dispensada também se dissipe ${ }^{19}$.

O monumento moderno, nasce portanto, como um provisório e propositado objeto catexizado, ele é desenhado para isso, com a finalidade (terapêutica?) de encadear na vida da cidade dois imperativos: lidar com as provas reais do terror e reinstaurar nela uma civilidade lúcida e consciente (se eles cumprem isso, é o tema de outro debate que extrapola o escopo desse ensaio). Minha segunda hipótese é a de que a existência do monumento moderno, que assimilou essa percepção da perda, depende dela para se pensar a partir de uma linha de risco, que vem a ser sua destinação também ao "leigo": aquele que supõe lidar de fora ou indiretamente com o seu tema, que apenas compreende ou não se pergunta o significado dele se autorizar sentir menos, crendo que esse abismo se restringe ao outro. Há, de fato, o exercício de tradução, de verter para formas uma experiência que nunca é alheia, perceba-se isso ou não. Terror e tremor: esse gesto procura recolocar ao cidadão, ao passante e ao visitante sua ética, tanto em relação ao passado quanto ao presente e futuro, concernente a responsabilidade de suas decisões. A opaca "poesia" desses monumentos - por isso eles precisarem parecer tão impessoais, tão intrusos e estraga-prazeres do hedonismo do predatório turismo globalizado - adverte-nos que a vida segue, mas impede a cosmética da metrópole passiva ao consumo "ingênuo" ou a neutralização confortável do solo onde pisamos; podemos um dia afundar nele; nada nos garante que, sem um compromisso diário (tão diário quanto passar por essas obras no caminho do trabalho, da escola, ou de outra atração turística) com a humanidade, arrisca sermos os homenageados tombados em outra catástrofe futura.

Este é um artigo publicado em acesso aberto sob uma licença Creative Commons (cc))

19 Id. Ibid.: 442-3 (tradução inglesa: 255). 